\title{
IDL Particles Measurement
}

National Cancer Institute

\section{Source}

National Cancer Institute. IDL Particles Measurement. NCI Thesaurus. Code C116197.

The determination of the amount of intermediate density lipoprotein particles present in a sample. 